\title{
Simulation of the newly-built temporary cofferdam stability under the regular wave condition
}

\author{
Wenbin $\mathrm{Liu}^{1,2,3,4^{*}}$ \\ ${ }^{1}$ Tianjin Port Engineering Institute Co., Ltd. Of CCCC First harbor engineering Co., Ltd., Tianjin, 300222, China \\ ${ }^{2} \mathrm{CCCC}$ First Harbor Engineering Company Ltd., Tianjin, China \\ ${ }^{3}$ Key Laboratory of Port Geotechnical Engineering, Ministry of Communications, PRC, Tianjin, China \\ ${ }^{4}$ Key Laboratory of Port Geotechnical Engineering of Tianjin, Tianjin, China
}

\begin{abstract}
The lateral cyclic wave force challenges the newly-built temporary cofferdam seriously. This paper simulated and assessed the movement of the plugged-in steel cylinder affected by the regular wave force with finite element method. The FEM analysis was conducted for an actual case, and the conclusions may show its advantages in the design work.
\end{abstract}

\section{Introduction}

The plugged-in steel cylinder is a new type island wall and performs well in many important projects. The practical case, which is used as a background in this paper, is in the Lingdingyang sea. The seabed surface elevation is $-2.5 \mathrm{~m}$. In practice, the dewatering method was applied to reduce the elevation of the surface of the seawater of the man-made island construction area, which is surrounding by the circle of the plugged-in cylinders, down to $-4.0 \mathrm{~m}$. The properties of soil layers in the engineering case are shown in Table 1. The design value of the regular high- and low-water level is $1.67 \mathrm{~m}$ and $-0.9 \mathrm{~m}$, respectively. The thickness and outer diameter of the plugged-in steel cylinder are $0.019 \mathrm{~m}$ and $15 \mathrm{~m}$, respectively. The whole steel cylinder is $19 \mathrm{~m}$ high, and the elevation of the top of all cylinders keeps at 3.0 $\mathrm{m}$. The steel cylinders are welded one by one with steel arches. The area inside the steel cylinder and the gap surrounding by arches and cylinder are filled with sand treating by vibrocompaction technology.

Table 1. Soil parameters

\begin{tabular}{|c|c|c|c|c|}
\hline Layer & $\begin{array}{l}\text { Elevation of the bottom of the } \\
\text { plugged-in cylinder } \\
\text { (m) }\end{array}$ & $\begin{array}{l}\text { Sub-merged } \\
\text { weight } \\
(\mathrm{kN} / \mathrm{m} 3)\end{array}$ & $\begin{array}{l}\text { Cohesion } \\
(\mathrm{kN} / \mathrm{m} 2)\end{array}$ & $\begin{array}{l}\text { Angle of the inner } \\
\text { friction } \\
\left({ }^{\circ}\right)\end{array}$ \\
\hline Mud & -7.58 & 15.1 & 5.1 & 2.3 \\
\hline Clay & -13.68 & 18.9 & 26.1 & 11 \\
\hline Gravel sand & -21.28 & 20.5 & 1 & 30 \\
\hline Silty clay & -24.48 & 18.3 & 38.3 & 18.8 \\
\hline $\begin{array}{l}\text { Completely weathered } \\
\text { granite }\end{array}$ & -40 & 21 & 30 & 15 \\
\hline $\begin{array}{l}\text { Backfill sand } \\
\text { (Inside of cylinder) }\end{array}$ & & 20.5 & 1 & 30 \\
\hline
\end{tabular}

The remove of the soil inside of the newly-built temporary cofferdam is executed layer by layer. The elevation of the slope top is $-8 \mathrm{~m}$, and this layer is $10 \mathrm{~m}$ wide in horizonal direction. The slope ratio of this layer is $1: 1.5$. The slope ratio of next lower slope is $1: 3$. The elevation of the slope bottom is $-22 \mathrm{~m}$. Figure 1 shows the designed profile of the plugged-in steel cylinder and the nearby soil.

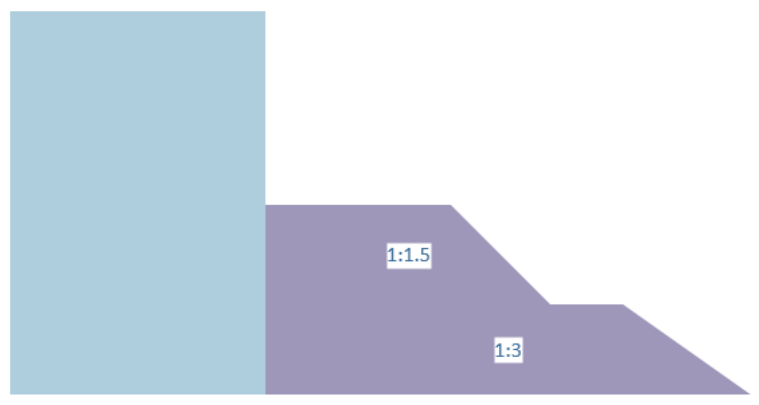

Figure 1. The profile of the plugged-in steel cylinder and the nearby soil 


\section{Stability analysis}

The FEM analyses was conducted with the help of the commercial software PLAXIS 3D. The model is $100 \mathrm{~m}$ long, $31 \mathrm{~m}$ wide and $15 \mathrm{~m}$ deep. The plugged-in cylinder rests on gravel sand layer. The wave force was $4600 \mathrm{kN}$ acting laterally on one side of the plugged-in cylinder calculated based on the code 'Hydrologic specifications for ports and waterways' (JTS 145-2015). Fig.2 illustrates the displacement of the foundation. And the displacement of the plugged-in cylinder is displayed in Fig. 3 and 4.

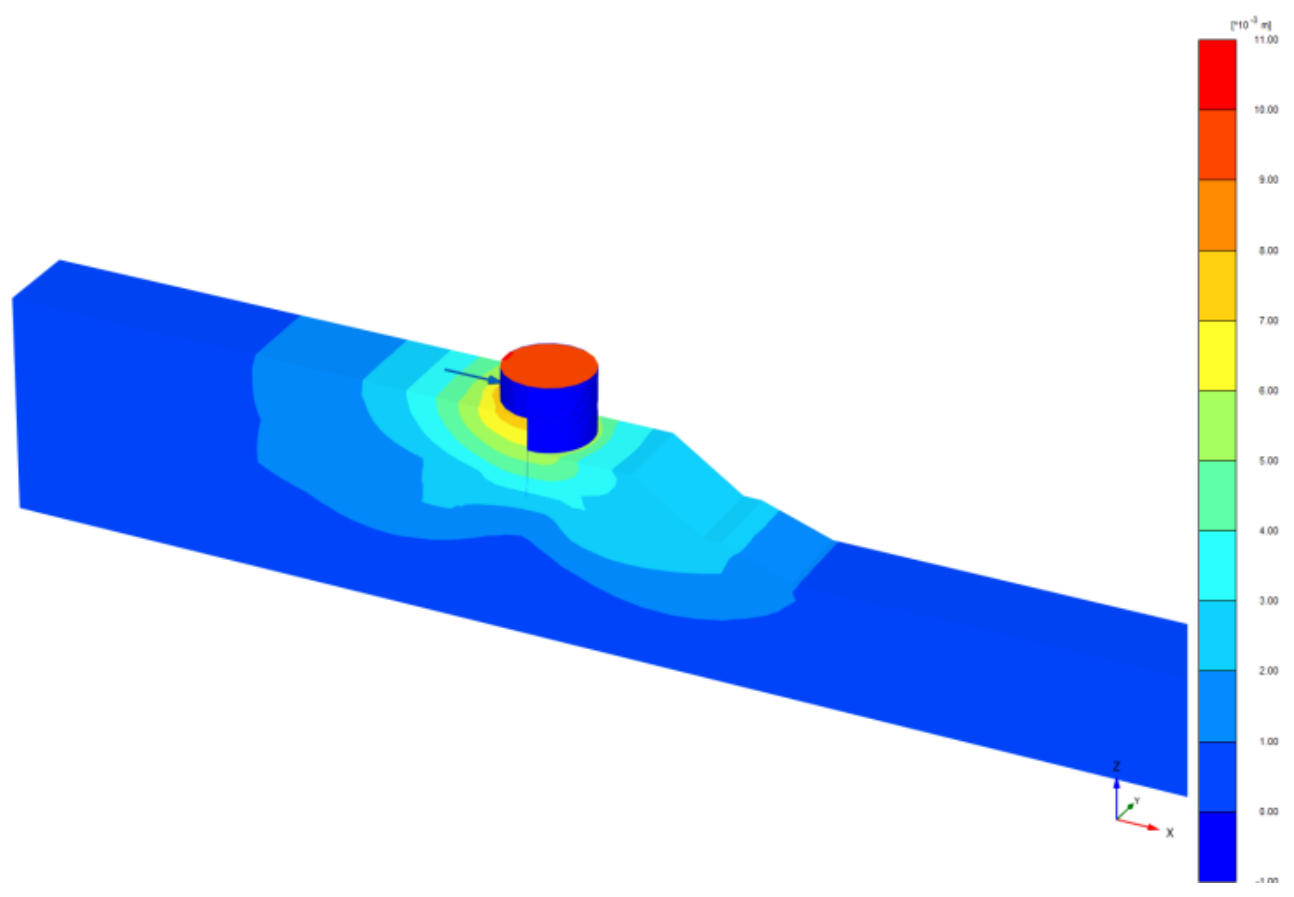

Fig. 2 The displacement of soil around the plugged-in cylinder

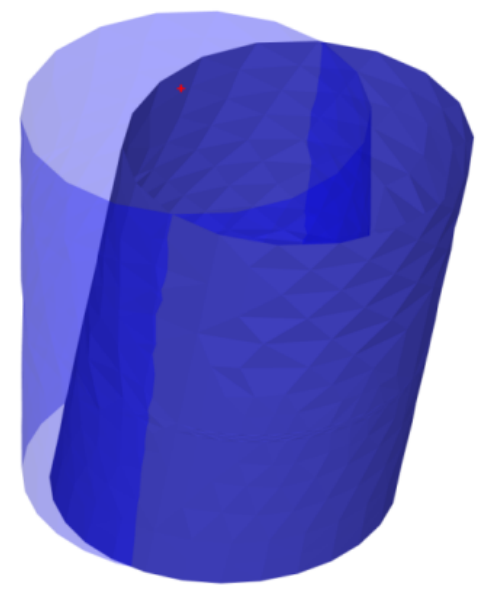

Figure 3 The profiles of plugged-in cylinder before and after deformation 

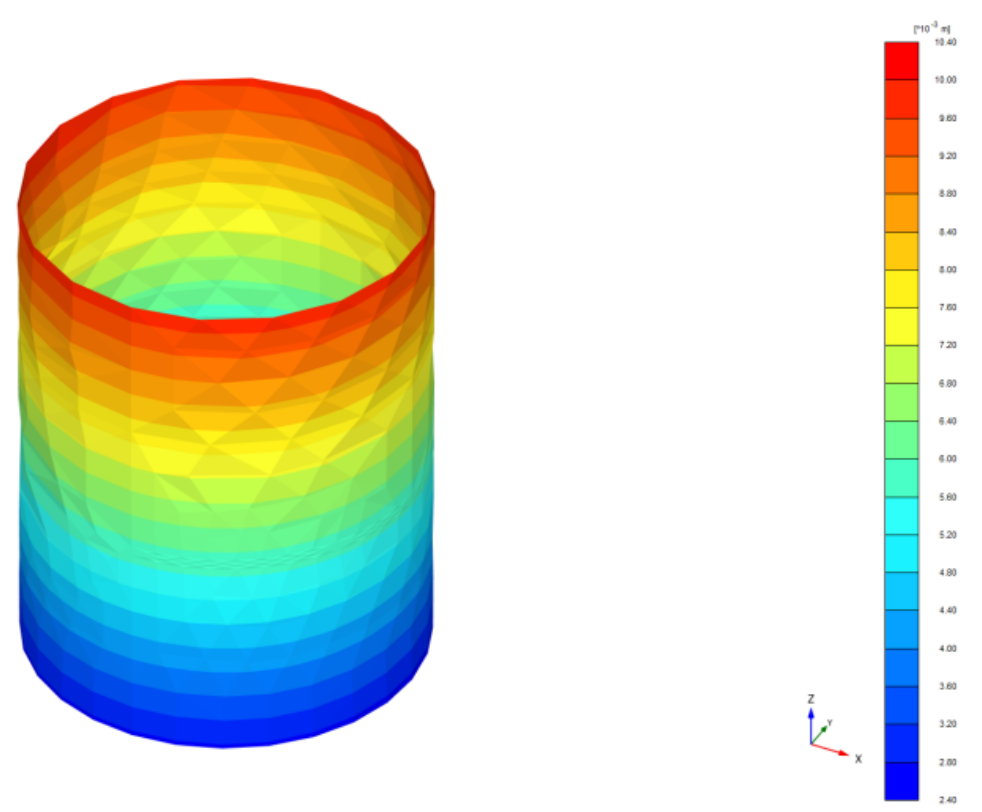

Figure 4 The lateral displacement of the plugged-in cylinder

The FEA results indicate that the displacement of the cylinder top is $1 \mathrm{~cm}$ affected by the regular wave force and the corresponding safety coefficient is 2.3 under the situation that the height of plugged-in cylinder equals to $19 \mathrm{~m}$ and the diameter is $15 \mathrm{~m}$.
Two additional cases are established to analyse the influence of the height of the steel cylinder on the stability under the regular wave condition. The height of the three cases and their corresponding safety factors are displayed in Table 2 .

Table 2 The influence of the cylinder height on

\begin{tabular}{lllll}
\hline Case number & Resting layer & Elevation of cylinder bottom & Height of cylinder & Safety factor \\
\hline 1 & Gravel sand & $-16 \mathrm{~m}$ & $19 \mathrm{~m}$ & 2.24 \\
2 & Gravel sand & $-15 \mathrm{~m}$ & $18 \mathrm{~m}$ & 2.22 \\
3 & Gravel sand & $-14 \mathrm{~m}$ & $17 \mathrm{~m}$ & 2.20 \\
\hline
\end{tabular}

Table 2 shows that the safety coefficients of pluggedin cylinders with different heights are different even though the foundation are same. The safety coefficient rises due to the increment in the height of the cylinders, and it goes down to 2.2 if the height of the plugged-in cylinder reduces down to $17 \mathrm{~m}$.

\section{Conclusions}

Our paper simulated the movements of the plugged-in steel cylinders with the help of the data from an actual engineering case, and we can learn these points from this analysis.

(1) The maximum lateral displacement on the top of the steel cylinder is $1 \mathrm{~cm}$ for this engineering case under the condition that the height, diameter and thickness of the plugged-in cylinder is $19 \mathrm{~m}, 15 \mathrm{~m}$ and $0.0019 \mathrm{~m}$. The corresponding safety coefficient is 2.3 .

(2) The safety of the plugged-in steel cylinder is influenced by the height of cylinder. The safety coefficient goes up due to the increment in the cylinder height when the foundation and the wave condition remain unchanged.

\section{References}

1. Wang YZ, Zhu ZY, Zhou ZR. Dynamic response analysis for embedded large-cylinder breakwaters under wave excitation[J]. China Ocean Engineering, 2004, 18 (4): 585-594.

2. Meng QW, Wang YZ. Coupled analysis of contactface element and elastic nonlinear element for interaction of large-diameter shell and soil body[J]. China Harbour Engineering, 1999, 2.

3. Zhu ZY, Dynamic response of large diameter cylinder breakwater structure under the wave impact [D]. Tianjin, 2003.

4. Sun KL. The interaction between plugged-in cylinder and soil [D]. Tianjin, 1999.

5. Chen FQ, Gong XN. Analysis of large cylinder wharf structures using finite element method[J]. Hydro-Science and Engineering, 2001, 4: 37-40. 